Melo, M.I.O.; Dias, K.S. Parques urbanos, a natureza na cidade: práticas de lazer e de turismo aliadas à cidadania. Revista Brasileira de Ecoturismo, São Paulo, v.6, n.5, nov-2013/jan2014, pp.942-957.

\title{
Parques urbanos, a natureza na cidade: práticas de lazer e de turismo aliadas à cidadania
}

\author{
Urban parks, nature in the city: practices of recreation and tourism allied \\ to citizenship
}

\section{Mariana Inocêncio Oliveira Melo, Karina e Silva Dias}

\begin{abstract}
RESUMO
A pesquisa trata de uma investigação de cunho qualitativo que busca analisar a (re) configuração dos parques urbanos na cidade, bem como sua influência para a sociabilidade na urbe, a partir das práticas de lazer e de turismo. Os parques urbanos são representativos para o lazer da cidade por serem capazes de estabelecer relações sociais por meio das atividades esportivas, culturais, educativas, artísticas, ambientais e contemplativas. Desenvolve-se o artigo com uma revisão literária em torno do tema, por meio de discussões teórico-conceituais sobre os parques urbanos, turismo, lazer, cidade, cidadania, turismo cidadão, paisagem e natureza. O presente artigo tem, portanto, a intenção de apresentar as diversas possibilidades de apropriação e configuração espacial dos parques urbanos na cidade; as práticas de lazer e de turismo e suas influências para a (res)significação da experiência na urbe; a ampliação da cidadania aliada ao turismo e ao lazer; a influência dos parques urbanos na (re)configuração das paisagens na cidade e, finalmente, os fragmentos de natureza no meio urbano.
\end{abstract}

PALAVRAS-CHAVE: Turismo; Lazer; Parques Urbanos; Cidade.

\section{ABSTRACT}

This qualitative research seeks to analyze the reconfiguration of urban parks, as well as their influence on the sociability in the city through the practices of leisure and tourism. The urban parks are representative for city leisure because they are able to establish social relations through sport, cultural, educational, artistic, environmental and contemplative activities. This article is developed by making a review of the literature on this theme through theoretic-conceptual discussions involving urban parks, tourism, leisure, city, citizenship, national tourism, landscape and nature. This article therefore, aims to present the various possibilities of spatial appropriation and configuration of city parks; the practices of leisure and tourism and their influences in redefining the city experience; the increase of citizenship allied to tourism and leisure, the influence of the urban parks in the reconfiguration of the city landscapes and finally, the fragments of nature in the urban environment.

KEYWORDS: Tourism; Leisure; Urban Parks; City.

Página 942 Revista Brasileira de Ecoturismo, São Paulo, v.6, n.5, nov 20I3-jan 2014, pp.942-957.

Sociedade Brasileira de Ecoturismo. Rua Dona Ana, 138, Vila Mariana, São Paulo, SP - Brasil. E-mail: rbecotur@sbecotur.org.br; Tel. (55-II) 99196-7685 


\section{Introdução}

O presente artigo trata do turismo e lazer na cidade, representado pelos parques urbanos, com o seguinte objetivo: estudar a (re)configuração dos parques urbanos na cidade, bem como sua influência para a sociabilidade na urbe, por meio das práticas de lazer e de turismo.

No que concerne ao contexto histórico, vale observar que o turismo nasceu, cresceu e se desenvolveu com o capitalismo industrial. A partir da Revolução Industrial as viagens tornaram-se expressivas, aparece a busca pelo descanso e a fuga do dia a dia que rompam com o universo do cotidiano, tornando-se fonte de equilíbrio para a qualidade de vida dos citadinos. Ademais, outro fator determinante para o surgimento do lazer é o avanço tecnológico. Salienta-se que, com a urbanização e industrialização, estes dois fenômenos - turismo e lazer - cresceram como atividade e também como demanda. São práticas sociais baseadas na busca de diversos atrativos - histórico, arquitetônico, cultural, dentre outros.

O artigo é estruturado em quatro seções: 1 - Parques urbanos: representação de espaço público no meio urbano, - discorre sobre a criação dos parques urbanos para promoverem a socialização e a construção do espaço com a presença da natureza, decorrente do crescimento das cidades, tanto no aspecto espacial quanto na demanda por infraestrutura e/ou serviços urbanos. 2 - Socialização na cidade: práticas de lazer e turismo, - apresenta uma revisão bibliográfica que analisa os espaços das cidades que são referências para o turismo e o lazer, sendo os parques urbanos uma representação de espaço público com a presença da natureza para a realização destas atividades no meio urbano. 3 - Cidadania: possibilidades para pensar o turismo e o lazer, - sintetiza a importância da conscientização cidadã, praticada principalmente pelos frequentadores dos parques urbanos, para que tenham uma postura de minimizar os impactos no local, bem como respeitar o princípio de que se trata de um bem comum. Expõe, ainda, uma discussão da importância dos espaços urbanos no tempo livre dos citadinos para a consecução de atividades de lazer, transformando-se em turistas cidadãos. 4 - Paisagem e natureza na cidade, reflete a (re)configuração nas paisagens urbanas e seus aspectos estruturais e estéticos como um atrativo para o turismo e o lazer. Mescla-se, ainda, uma abordagem relacional entre a natureza e a cidade, à luz do olhar diferenciado sobre a natureza como parte do espaço urbano e sua relação com os citadinos e os turistas.

Desse modo, o artigo relaciona os parques urbanos com o lazer e o turismo para proporcionar reflexões na dimensão urbana, com preposições teórico-conceituais para discutir a influência na (re)configuração das paisagens nas cidades, a presença da natureza no meio urbano, a diversidade de atividades realizadas nestes espaços, bem como estas atividades ampliam a cidadania e (re)significam a experiência na urbe. Assim, investigá-los é refletir acerca do planejamento dos parques urbanos enquanto ferramenta benéfica para recrear-se, divertir-se e entreter-se individualmente ou em grupo, adquirindo conhecimento e vivência - social e cultural ao experimentar, conviver e vivenciar esses espaços. 


\section{Parques urbanos: representação de espaço público no meio urbano}

No final do século XVIII, inicia-se na Europa, a Revolução Industrial, influenciando drasticamente variações espaciais, devido ao abandono das zonas rurais e a expansão das cidades, motivando uma série de transformações de ordem econômica, política, social e técnica. À medida que as cidades cresciam e a população demandava infraestrutura, aumentavam as queixas sobre alguns aspectos urbanos (trânsito, poluição atmosférica, mau cheiro, barulho, espaços de miséria, etc.) e diminuíam os espaços com fragmentos de natureza disponíveis para a população, que foram substituídos por casas, ruas, comércios, dentre outros. Assim, teve início a preocupação com reformas sanitaristas ${ }^{1}$, por meio de leis de saúde pública, para a consecução de higiene/limpeza urbana e a construção de melhor infraestrutura. As queixas dos citadinos se estendiam também ao fato de a industrialização ter promovido o crescimento das cidades em detrimento dos espaços de natureza. Jardins particulares construídos no século XVII deram lugar às construções habitacionais e comerciais, no século XVIII. (SPIRN, 1995).

Com a compreensão da importância desses espaços, os habitantes passaram a exigir dos órgãos públicos e das instituições responsáveis a criação e a revitalização de ambientes de natureza, tais como, parques, jardins, bosques e ruas arborizadas que, espalhados pela cidade, atuam como "pulmões" das cidades. Assim sendo, a presença destes ambientes de natureza se tornou importante nos planos e projetos urbanos. Eles são capazes de romper com o universo do cotidiano, amenizando com os problemas de ordem física e psicológica da população, pois permitem a socialização e a contemplação/fruição de fragmentos da natureza.

Nessa perspectiva, os parques urbanos transcendem ao aspecto físico, pois promovem as questões intrínsecas a sua presença como a valorização do solo, pelo contato com a natureza e um espaço de socialização. Percebe-se, então, que os parques urbanos são como antídotos para os males urbanos: melhoram o clima, contrapondo-se à aridez provocada pelo excesso de construções urbanas; diminuem a poluição do ar; enfim, permitem o contato com a natureza, dentre outros. Neste sentido, os governos ampliaram os espaços com natureza das grandes cidades com o intuito de preservar o meio ambiente e promover a socialização dos trabalhadores com suas famílias, sendo os parques urbanos uma representação. Serpa (2007, p.70) ressalta que as construções dos parques estão ligadas ao poder: "concebido como equipamento urbano e recreativo, o parque público está ligado, sobretudo, a uma vontade política".

Ao longo da história, os parques urbanos assumem diferentes funções e usos, seguindo a influência da estrutura urbana, do fenômeno social e da preservação de áreas verdes. Eles não são submetidos a um padrão, pois se diferenciam quanto ao tamanho; funções; tipos de equipamentos; espaço de preservação ambiental; de socialização; dentre outros. Conforme Serpa (2007, p.69) "todos os parques públicos representam alegorias do tempo e dos poderes que os conceberam. [...] Espaço e tempo atuam concomitantemente nos parques públicos [...]'.

Página 944 Revista Brasileira de Ecoturismo, São Paulo, v.6, n.5, nov 20I3-jan 20I4, pp.942-957. 
A ideia de introduzir a natureza nos espaços urbanos estende-se aos planejadores do século XX. Esse período foi marcado por um crescimento intenso nas cidades, ocasionando superpovoamento e poluição dos meios naturais. Logo, foram construídos mais parques públicos, com a intenção tanto de atender aos habitantes pelo valor estético, cultural e de lazer - quanto pela constituição ambiental e pela influência na paisagem de seu entorno - supervalorizam as paisagens circundantes -, associando-se aos requisitos naturais, sociais, culturais e históricos (re)configurados nas paisagens das urbes. Franco (1997, p. 4) assevera que os parques passam a ser "...] o local da reciclagem urbana, tanto no sentido biofísico quanto no sentido sociocultural".

Em função do planejamento dos parques, de sua inserção nos espaços urbanos e de sua influência em seu respectivo entorno, Kliass (1993, p.31) aponta que:

[...] o parque é um fato urbano de relativa autonomia, interagindo com o seu entorno e apresentando em seu bojo condições de absorver a dinâmica da estrutura urbana e dos hábitos de sua população. [...] $\mathrm{A}$ inserção efetiva da dimensão ambiental no processo de planejamento e na práxis dos diversos setores intervenientes no desenvolvimento urbano pode garantir o aproveitamento do potencial paisagístico do sítio urbano, criando condições para dotar a cidade de parques.

$\mathrm{Na}$ primeira metade do século XIX, diante das dificuldades estruturais enfrentadas pelas cidades, com as péssimas condições de trabalho e habitabilidade das grandes cidades europeias, aconteceu a criação dos primeiros parques urbanos para os moradores comuns. De acordo com Serpa (2007, p. 45), os parques urbanos são definidos "como lugares naturais modificados pela ação do homem para fins estéticos". Assim, arquitetos e paisagistas devem possuir, além desta preocupação, a implantação de atividades educacionais para que os frequentadores adquiram conhecimento da importância da preservação da natureza e cultura.

Vale destacar que 0 artigo $2^{\circ}$ do Estatuto da Cidade (2001) "estabelece normas de ordem pública e interesse social que regulem o uso da propriedade urbana em prol do bem coletivo, de segurança e do bem-estar dos cidadãos, bem como do equilíbrio ambiental". O Estatuto mostra claramente dentro das funções sociais da cidade a necessidade da vida urbana de estar em contato com a natureza, levando a ideia de "proteção, preservação e recuperação do meio ambiente natural e construído, do patrimônio cultural, histórico, artístico, paisagístico e arqueológico" (art. $2^{\circ}$, inc. XII). Destarte, a presença da natureza é essencial no planejamento das cidades, pois é importante tanto em seus aspectos estéticos quanto por proporcionar um ambiente agradável, tornando-se uma fonte de equilíbrio e de qualidade de vida aos seus habitantes.

Serpa (2007, p.82) enfatiza a ideia de que "[...] o parque público contribui para melhorar a qualidade da vida urbana e oferece aos habitantes das cidades espaços recreativos e de lazer 'festivo". Depreende-se que os parques urbanos são espaços 
públicos de grande importância para a população, já que remetem às relações sociais com perspectiva de encontro e convivência entre os indivíduos de uma sociedade, por meio de práticas esportivas, culturais, educativas, artísticas, ambientais e educacionais. Sendo assim, são importantes na estrutura urbana por representar espaços para o lazer dos citadinos e pela presença da natureza no coração das cidades.

\title{
Socialização na cidade: práticas de lazer e turismo
}

Fuster apresenta o primeiro registro das palavras "tourism" e "tourist", revelado pelo Dicionário de Inglês da Oxford, em 1800, apresentando os seguintes conceitos:

Turismo: a teoria e prática de viajar, deslocar-se por lazer. Uso, depredação. Turista: aquele que faz um passeio ou excursão, aquele que faz isto para o lazer; aquele que viaja a lazer ou cultura visitando diversos locais, de acordo com seus objetivos, interesses, tipos de paisagens ou pelo seu gosto (FUSTER, 1974, p. 21, tradução nossa).

O turismo é uma atividade que envolve questões histórico-sociais que pressupõem deslocamentos de indivíduos em tempos e espaços diferentes daqueles dos seus cotidianos, que, por sua vez, possibilitam o afastamento concreto e simbólico do dia a dia. Segundo Gastal e Moesch (2007, p.12) "[...] o Turismo se constitui em um fenômeno sociocultural de profundo valor simbólico para sujeitos que o praticam". Simbólico por seus valores de uso e afetividade, que ocasionam ao indivíduo sensações de surpresas, sentimentos e comportamentos, levando-os a (re) pensar, (re)ver e (re)avaliar não só o momento vivenciado, mas, também a vida. Ressalta-se, ainda, que essas experiências são proporcionadas tanto aos visitantes quanto à comunidade local.

Ainda assim, o que possibilitou o nascimento, crescimento e desenvolvimento do turismo e de muitas outras áreas foi o capitalismo industrial. Se antigamente a religião, saúde e estudos eram os incentivos das viagens, a partir da Revolução Industrial, elas tornam-se expressivas e muda para a busca da quebra de rotina; o descanso; a recreação; o sentimento de liberdade, com o propósito de repor as energias e a fuga do dia a dia. Vale lembrar que este período é marcado por trabalhos cansativos e de elevada carga horária.

Moesch (2002, p.9) descreve o turismo dentro dos aspectos sociais, culturais e históricos, afirmando que:

\begin{abstract}
é uma combinação complexa de inter-relacionamentos entre produção e serviços, em cuja composição integram-se uma prática social com base cultural, com herança histórica, a um meio ambiente diverso, cartografia natural, relações sociais de hospitalidade, troca de informações interculturais. O somatório desta dinâmica sociocultural gera um fenômeno, recheado de objetividade/subjetividade, consumido por milhões de pessoas, como síntese: o produto turístico.
\end{abstract}

Página 946 Revista Brasileira de Ecoturismo, São Paulo, v.6, n.5, nov 20I3-jan 2014, pp.942-957. 
O turismo, portanto, pode ser entendido como: o deslocamento fora do seu local de residência; o tempo de permanência no destino com um período determinado e não duradouro; a viagem indo para o destino; as atividades realizadas durante a estadia e o contato com a cultura e historicidade da comunidade. Qualquer que seja o motivo para a viagem, o turismo abarca os serviços e produtos criados para satisfazer as necessidades dos turistas.

Nessas circunstâncias, surgiram às reivindicações sociais para diminuir a carga horária de trabalho, obter férias, folga nos finais de semana e aposentadoria, pois no início da industrialização, o trabalho era marcado com jornada de 15 a 16 horas, salário miserável, sem descanso e por um período muito longo da vida. Nesse sentido, verifica-se que o tempo livre tanto para o lazer quanto para o turismo é conquistado com a redução da jornada de trabalho. Dumazedier (2004, p.25) salienta que "a necessidade de lazer cresce com a urbanização e a industrialização".

O lazer é uma forma de melhorar a qualidade de vida da população das grandes cidades e deve ser considerado como suprimento às necessidades físicas e psíquicas, como confirma Werneck (2000, p. 140). Neste sentido, "[...] o homem deve ser visto como um todo e não dividido em corpo e mente, emoção e racionalidade, indivíduo e ser social' (MARCELLINO, 2003, p.37).

Do ponto de vista do desenvolvimento cultural do lazer, Dumazedier (1980) divide-o em cinco categorias: físico, prático, artístico, intelectual e social. Essas categorias não devem ser lembradas isoladamente, pois partem das opções pessoais das atividades de lazer, o que nos leva a pensar o homem de maneira integrada corpo e mente - e que as distinções das categorias são realizadas pela característica predominante que se busca no desenvolvimento da atividade, tendo-se em vista que estão interligadas.

Os interesses físicos são caracterizados como: "[...] a participação ativa e voluntária do indivíduo nas atividades relacionadas com a cultura física, isto é, um novo enfoque da prática esportiva e da assistência ao espetáculo" (DUMAZEDIER, 1980, p.112). Eles são caracterizados como a prática dos exercícios físicos e esportivos, vinculados à participação consciente e voluntária na vida social e cultural.

Os interesses práticos, por sua vez, são atividades manuais (bricolage ${ }^{2}$, culinária ao domingo, artesanato, jardinagem, etc.), produtivas e, em sua maioria, relacionadas a obrigações familiares com caráter utilitário - depende das obrigações familiares ou semi obrigatórias - e desinteressadas - realizam-se no espaço e tempo de lazer ou do semilazer ${ }^{3}$ (DUMAZEDIER, 1980). No que tange aos tipos de atividades, destaca-se que o trabalho manual doméstico é uma oportunidade para estabelecer possível equilíbrio entre as relações profissionais e familiares, e, ainda, faz com que os indivíduos se esqueçam dos problemas econômicos, trabalhistas, escolares, etc.

Com relação aos interesses artísticos, por sua vez, averigua-se a divulgação e a progressão cultural. Diante do exposto, Dumazedier (1980, P.135), apresenta dois movimentos: "[...] a democratização das artes eruditas e a promoção das formas de 
arte tradicional e popular na cultura de hoje". Para tanto, é necessário divulgar as artes em diversos espaços - lugares públicos (jardins, praças, parques, ruas, mercados, recintos abertos, etc.), cinema, rádio, teatro, museu, etc., - para atingir diferentes classes populacionais - sociais, etárias e educacionais - despertando o interesse e o gosto pela arte.

De acordo com os interesses intelectuais, as atividades são voluntárias, ou seja, não incluem atividades escolares ou universitárias. Nos quais são motivadas por uma inclinação pessoal e pela paixão capaz de passar conhecimento, informação e aprendizagem, como: leitura, filme, teatro, dentre outros. Com relação a diferenciação das atividades de lazer voltados a interesses artísticos, esses envolvem aspectos subjetivos - o encantamento, a beleza e a estética -, enquanto que os intelectuais abrangem a objetividade, pelo fato de relacionarem-se às questões documentárias, científicas e didáticas.

Por último, os interesses sociais são compostos pela análise do desenvolvimento de sociabilidade nas atividades de lazer de interesses físicos, atividades prático-manuais, espetáculos artísticos e intelectuais, sendo necessário observar os interesses sociais comuns e os específicos de cada atividade (DUMAZEDIER, 1980). É importante salientar que o lazer associado à prática social é de grande importância, pois leva o indivíduo a parar e observar, desse modo passa a (re)pensar e (re)avaliar o local, a cultura, o modo de vida dos autóctones, etc., proporcionando a formação de um novo pensamento, sentimento, comportamento social e cultural.

Em suma, a socialização é importante em todos os interesses do lazer por depreender as relações desenvolvidas por indivíduos ou grupos de pessoas, ocasionando relações e interações sociais, caracterizadas pelos sentimentos dos participantes e o grau de interesse e prazer proporcionados.

Compartilhando da ideia de Camargo (2003), acredita-se que pode ser acrescentada mais uma área de interesse cultural nessa classificação, o turístico, marcado pela prática de atividade voluntária e prazerosa, ligada ao campo educativo, relacionando-o com a participação social e lúdica. $O$ referido interesse possibilita a abertura para uma vida cultural e educacional intensa e diversificada. Desse modo, conjectura-se que o lazer composto pelo aspecto cultural e pela prática social interfere no desenvolvimento pessoal dos indivíduos, logo é um instrumento de mudanças.

O avanço do fenômeno turístico, por meio de suas peculiaridades, permite 0 seu desenvolvimento em diversas regiões, e "[...] são justamente os valores e os traços culturais com especificidades territoriais que fazem a existência dos lugares" (CASTROGIOVANNI, 2001b, p.134). É necessário um planejamento adequado para preservar tanto os aspectos sociais, culturais, históricos e naturais, quanto proporcionar benefícios à população, seja nos aspectos do contato com os turistas, seja com relação à exploração e desenvolvimento turístico. Ressalta-se, ainda, que, quando há controle no desenvolvimento do turismo, essa atividade traz benefícios à vida econômica, política, cultural e social da comunidade.

A partir da década de 1950, o turismo transformou-se significativamente pelos 
aspectos socioeconômicos e culturais. Em contrapartida, a partir de 1960, desenvolveu-se como atividade de lazer, atraindo milhões de pessoas, transformando -se em grande valia tanto para a economia local quanto internacionalmente. Entretanto, as atividades turísticas acrescidas com a massificação são praticadas de forma padronizada.

Somente no início dos anos de 1970 é que as pessoas conscientizam-se dos efeitos físicos, psicológicos e sociológicos do turismo, como a devastação dos ambientes naturais, o uso desenfreado das paisagens e a influência sobre a vida dos autóctones. Enfim, passaram a se preocupar com o impacto do produto turístico na sociedade, como relata Krippendorf (2009). No final do século XX as pessoas começaram a perceber que as necessidades psíquicas e sociais - bens imateriais são mais importantes do que as necessidades materiais.

Depreende-se que as viagens reconstroem as formas físicas e mentais, pois oferecem às pessoas o descanso para enfrentar a correria do cotidiano. Isto é, "as viagens [...] devem reconstruir, recriar o homem, curar e sustentar o corpo e a alma, proporcionar uma fonte de forças vitais e trazer um sentido à vida" (KRIPPENDORF, 2009 , p.34). O autor destaca, ainda, que "a viagem deve contribuir para contrabalançar os déficits e as privações" (Ibidem, p.45), capaz de transformar a vida. Estes momentos são representados pelo desfrute dos encantos, das belezas, das aventuras e dos deleites.

Desse modo, o tempo livre "[...] não é somente uma oportunidade de descansar para voltar com novas energias para o trabalho, mas sim uma oportunidade para o desenvolvimento pessoal, para experimentar e vislumbrar novas realidades, para aprender" (MOLINA, 2005, p.39, tradução nossa). Aproveitar o tempo livre de forma mais produtiva, com o intuito de adquirir novas informações e conhecer culturas distintas, a fim de se tornarem mais críticas, tornou-se um imperativo para as pessoas. Sucede-se, assim, o aprimoramento das reflexões sobre as informações diárias confrontando-as com a realidade. Dessa forma, Molina (2005, p.59, tradução nossa) reitera que:

[...] o turismo é capaz de proporcionar aos indivíduos uma série de experiências que ajudam a melhorar a compreensão de si e do mundo ao seu redor, ajudá-los a melhorar sua comunicação com os outros, para valorizar suas próprias habilidades e competências e estabelecer compromissos com vários aspectos críticos de sua realidade e da realidade social.

Neste sentido, as viagens têm como escopo oferecer bem estar e qualidade de vida para os indivíduos, pelo fato de proporcionarem a vivência de valores que contribuam para mudanças de ordem social e cultural. Segundo Ribeiro (2001, p.146), a atratividade turística nos centros urbanos "[...] está centrada no grau de interesse arquitetônico, histórico e cultural que o patrimônio histórico e demais componentes da paisagem urbana geram na visitação e nos serviços existentes, enquanto atração de "consumo cultural"." O turismo e o lazer nas cidades transformam suas antigas 
paisagens em novos atrativos, trazendo a valorização e embelezamento desses espaços; consequentemente, melhoram a qualidade de vida da população, proporcionam uma gama de atrativos turísticos e geram novas oportunidades econômicas.

Conforme Castrogiovanni (2001a, p.7), o turismo é significativo pelo fato das cidades serem "[...] espaços privilegiados quanto à concentração de atrações, serviços, simbolismos e produções culturais". Neste sentido, as cidades turísticas devem possuir a integração de três requisitos: ser atraentes, acessíveis e equipadas com instalações capazes de oferecer hospedagem temporária aos visitantes.

Ressalta-se que o turismo, muitas das vezes, tem o contato direto ou influenciam a comunidade, por isso os turistas precisam respeitar o próximo e o local visitado, baseando-se nos princípios de boa conduta, tais como: ir ao encontro do novo; respeitar as diferenças culturais e se possível aprender um pouco sobre elas; interagir com a comunidade visitada e não desprezar e ignorar a presença dela; preservar o ambiente natural, dentre outros. A atividade turística deve incentivar a preservação dos aspectos culturais, históricos, arquitetônicos, naturais, etc. Assim, adotam práticas que visem resgatar as significações da memória e da cultura da comunidade "impressa" na infraestrutura, nos aspectos naturais e sociais, nos traços, modo de vida e costumes, enfim, características da cultura local.

Com relação à importância das peculiaridades históricas e sociais pode mencionar, por exemplo, os patrimônios históricos localizados nos centros das cidades. Dessa forma, Ribeiro (2001, p.146) afirma que: "[...] é importante ressaltar que não há possibilidade de restauração, reabilitação e manutenção de toda e qualquer edificação por parte somente do poder público [...]'. Enfatiza-se que a construção e o planejamento das cidades devem estar em harmonia com o modo de vida da sociedade que está sempre em mudança e dinamicidade, então quando a comunidade conhece a importância e a relevância da estrutura arquitetônica de sua cidade ajuda a preservá-la.

Ademais, é importante o tratamento geográfico dos espaços urbanos, com o intuito de desvelar a (re)utilização de locais, que antes eram degradados, ocasionando a valorização da vida cotidiana e da urbe. Os lugares turísticos geralmente são escolhidos e admirados por suas paisagens, sobressaindo os aspectos visuais mais desejáveis e atraentes para a indução ao consumo.

Concomitantemente, Marcellino (1996, p.8) reitera que a descrição das atividades de lazer são realizadas levando em consideração o aspecto atitude que "será caracterizado pelo tipo de relação verificada entre o sujeito e a experiência vivida, basicamente a satisfação provocada pela atividade", que é capaz de proporcionar o desenvolvimento pessoal e social. Por conseguinte, o lazer e o turismo contribuem na educação, pois cooperam para a formação - física, intelectual e moral do indivíduo.

As autoras Gastal e Moesch (2007) avançam no conceito de turismo, ao relacionarem a ideia do citadino em apropriar-se do local onde se mora no seu tempo 
de lazer, quebrando o modelo existencial da sociedade industrial criticado por Krippendorf (trabalho - moradia - lazer - viagem), de acordo com o qual o lazer com o restabelecimento do equilíbrio físico e emocional só seria possível em lugares distantes da própria residência ${ }^{5}$. Trata-se, assim, do conceito de turista cidadão, ao apropriar-se das circunstâncias espaciais e temporais de sua cidade estabelecendo a relação de pertencimento e identificação.

\section{Cidadania: possibilidades para pensar o turismo e o lazer}

Com o surgimento das cidades inicia-se a ideia de cidadania e tem como fundamento a alegação de que todos são iguais, perante a lei. Desde a Grécia (polis grega ${ }^{6}$ ) - local onde se originou a ideia de cidadania - reflete-se uma discrepância entre a teoria e a prática, na qual há a discriminação e distinção entre os cidadãos, como exemplo, a exclusão feminina, escravos e pessoas não proprietárias de bens materiais Concernente ao direito à cidadania pode-se inferir que é um processo histórico e de conquista popular, no qual a sociedade adquire progressivamente 0 direito de pensamento, consciência, opinião, religião e liberdade de expressão

A concepção de cidadania é composta pelos direitos e deveres dos indivíduos, construída coletivamente e em busca de uma sociedade melhor. Todos os homens são iguais, permitindo a todos os direitos civis, políticos e sociais ${ }^{7}$ (COVRE, 2001). Logo, os três direitos possuem relação recíproca e não podem ser desvinculados.

Após o término da Segunda Guerra Mundial, a Organização das Nações Unidas (ONU) redige uma Carta dos Direitos Humanos, buscando superar a tensão do conceito de cidadania relacionando-o com a questão de que a igualdade deve ser um direito de todas as pessoas, sem distinção. Esta percepção é reiterada pelo artigo $1^{\circ}$ da Declaração Universal dos Direitos Humanos, aduzindo que: "todos os seres humanos nascem livres e iguais em dignidade e em direitos. Dotados de razão e de consciência, devem agir uns para com os outros em espírito de fraternidade" (art. $1^{\circ}$ ). Concernente ao direito à cidadania pode-se inferir que é um processo histórico e de conquista popular, no qual a sociedade adquire progressivamente o direito de pensamento, consciência, opinião, religião e liberdade de expressão.

Evidencia-se, que as urbes são constituídas por intensas interações econômicas, sociais e culturais, por se tratarem de um ambiente que contêm pessoas de diferentes etnias, religiões, níveis educacionais, valores culturais, línguas, dialetos, dentre outros, permitindo-se constantes combinações de padrões, valores, costumes e modos de viver. Neste sentido, os parques urbanos são espaços que facilitam a interação social na cidade e promove a interação entre os citadino e os turistas.

Evidencia-se que a cidade é fragmentada e diversificada, constituindo o espaço urbano por fixos - praças, edifícios, monumentos, etc. - e fluxos, que são as ideias, comportamentos e culturas que movimentam e marcam o território, conforme Gastal e Moesch (2007). As pessoas fazem parte do fluxo, conquanto, a participação e presença delas no planejamento, reestruturação e estratégias econômicas da urbe 
são de grande importância, desde que compreendam e dominem os processos envolvidos e a realidade concreta dos espaços onde estão inseridas. Salienta-se que, ao realizar-se o planejamento urbano, a cidade deve, primeiramente, ser atrativa à própria população, proporcionando-Ihes satisfação.

Dessa forma, ao apropriar-se das paisagens que compõem sua cidade, a comunidade exerce a ideia de cidadania. Ao usufruir destes locais, o citadino realiza a prática do turismo cidadão, considerado como:

[...] aquele morador da localidade que vivencia práticas sociais, no seu tempo rotineiro, dentro de sua cidade, de forma não rotineira, onde é provado em relação à cidade. Turista cidadão é aquele que resgata a cultura da sua cidade, fazendo uso do estranhamento da mesma. Este estranhamento inicia no momento em que o indivíduo descobre, no espaço cotidiano, outras culturas, outras formas étnicas e outras oportunidades de lazer e entretenimento. Quando se encontra na situação de turista cidadão, este sujeito aprende a utilizar os espaços ambientais, culturais, históricos, comerciais e de entretenimento com uma percepção diferenciada do seu cotidiano (GASTAL; MOESCH, 2007, p. 65).

Diante do exposto, ao apropriar-se das paisagens os turistas cidadãos avançam da simples apropriação dos fixos para integrar-se dos fluxos de ideias e expressões culturais, manifestadas na localidade. A diversidade e interação cultural das cidades ocasionam o desafio da "construção e ao exercício da cidadania em sociedades multiculturais" (GASTAL; MOESCH, 2007, p.18), pois possuem um grande número de habitantes com diversidade cultural, ocasionando intensas interações.

A prática do turismo cidadão aprofunda laços com a cultura local, no qual estabelece o sentimento de identidade e pertencimento, por conseguinte conscientiza-se da importância e do respeito que se deve ter com a cultura que se encontra em constante construção social. Segundo Gastal e Moesch (2007, p.66) "[...] a experiência do turista cidadão, carregada de subjetividade, se expressa, porém, objetivamente nas vivências ocorridas durante o tempo de lazer, no consumo de práticas de entretenimento, cultura e meio ambiente", sofrendo influencia de outras pessoas e do meio inserido.

Aplicar as questões de cidadania ao turismo e ao lazer significa considerar, em primeiro lugar, que estas atividades são caracterizadas pelo deslocamento no espaço próximo ou distante - de indivíduos ou grupo de pessoas que, ao se deslocar para local diferente do seu cotidiano, vivem o estranhamento e o contato com o diferente. Neste sentido, quando o visitante respeita e convive com a diferença da comunidade, entende-se que ele está praticando a cidadania.

\section{Paisagem e natureza na cidade}

Esta seção propõe uma reflexão sobre a natureza dentro da cidade e sua interrelação com a população. A ideia é retratar a presença da natureza no meio urbano, mas não aquela natureza intocada, em seu ritmo natural, e sim aquela incorporada à vida social. Busca-se desenvolver algumas reflexões sobre a paisagem e a natureza como parte do espaço urbano, especialmente suas inter-relações com a urbe e o contato com as pessoas da localidade e turistas. 
A autora Spirn (1995, p.15) apresenta pormenorizadamente a relação entre cidade e natureza, afirmando que:

A natureza permeia a cidade, forjando relações entre ela e o ar, o solo, a água e os organismos vivos em seu interior e a sua volta. As forças da natureza [...] reconhecidas e aproveitadas, representam um poderoso recurso para a conformação de um hábitat urbano benéfico; ignoradas ou subvertidas, ampliam os problemas que há séculos castigam as cidades, como enchentes, deslizamentos e a poluição do ar e da água.

Diante do exposto, pode-se constatar que a natureza se encontra todo o tempo em toda parte, porém, há uma crença de que a urbe está separada da natureza e, ao mesmo tempo, contrária a ela. Devido ao crescimento desenfreado das cidades os graves problemas ambientais urbanos tornaram-se crônicos, reafirmando a ideia de que é necessário planejamento e projetos, que constituem em intervenções nas paisagens e no modo de vida da sociedade. A cidade precisa ser reconhecida como parte da natureza, ou seja, que o espaço natural está dentro dela. Assim, a natureza é reconhecida como parte do ambiente e os empreendimentos humanos se adaptam a ela, respeitando sua estrutura física e geológica.

Ressalta-se, que é muito importante aos citadinos à preservação e construção de áreas com a presença da natureza, consequentemente para os turistas, por contrapor os ambientes urbanos, tornando-se um espaço de fruição, de contemplação e deleite, em especial, os parques urbanos. Silva (2004, p.52-53) enfatiza a ideia de que "a exploração turística de parques e áreas de conservação sustenta-se com os mesmos apelos do retorno ao natural e do contato com a natureza, mesmo quando inclui o homem", proporcionando uma vivência mais rica dentro da cidade. Esta busca de experiência nestes espaços desperta a valorização e compreensão da importância do ambiente natural no local em que vivem.

As cidades são compostas por diversos tipos de paisagens - históricas, culturais, artísticas e naturais - intrínsecas pelo seu valor de uso e valor afetivo, proporcionando às pessoas o sentimento de pertencimento ao local, uma vez que são contextualizadas e resultantes dos aspectos históricos, sociais, políticos, econômicos, naturais e culturais que compõem a forma organizacional e o modo de vida da sociedade. Assim, "a paisagem é resultado do acúmulo de ações temporais" (CASTROGIOVANNI, 2001, p.132). Segundo Silva (2004, p.51) o turismo modifica a natureza, para torná-la atrativa, afirmando que:

O turismo como atividade organizada no mundo contemporâneo tornou a natureza, de certa forma, mais 'doméstica', permitindo às pessoas comuns, não apenas aos aventureiros e exploradores ricos, o desfrute de paisagens selvagens com o conforto de uma viagem planejada e sem riscos. A natureza controlada e domesticada oferece, além do conforto, o contraponto necessário à exaltação da natureza selvagem e indômita imaginada pelos antigos exploradores. 
Por outro lado, antes de uma paisagem tornar-se turística ela é voltada para a comunidade. Neste propósito, "[...] a paisagem se revela em meio às situações rotineiras e banais, em um movimento acelerado de pontos de vista distintos; ela é passagem, um deslocamento do olhar" (DIAS, 2010, p.113). A autora sugere que "a experiência da paisagem no cotidiano se forja, então, na junção entre certa maneira de olhar e os caminhos percorridos. Ela tomaria forma a partir de detalhes corriqueiros que, por serem vistos e (re)vistos continuamente, se tornariam invisíveis aos nossos olhos" (p.113). E completa, ainda, que "[...] perceber uma paisagem é vislumbrar uma nova configuração do espaço de sempre" (p.114). Compreende-se que as paisagens do cotidiano da comunidade passam despercebidas por tornaremse habituais à sociedade.

Pressupõe-se que a paisagem vista, passa a existir com outras características específicas, a partir do momento em que "trabalhar com o invisível, o n[ã]o-visto, é se dar conta de que vemos e de que, acima de tudo, não vemos; de que, na rotina, experimentamos frequentemente um estado de cegueira" (DIAS, p. 115-116, grifo da autora), entretanto quando os citadinos veem as paisagens rotineiras, passam a desfrutá-las , contemplá-las e usá-las como espaço de lazer, descanso e recreação. Assim, compreendem a contextualização das paisagens de sua cidade, consequentemente conhecem e entendem a história, cultura e contextualização intrínsecas as paisagens presentes no dia a dia.

\section{Conclusão}

As cidades oferecem uma gama de produtos e serviços - infraestrutura, facilidade de transporte, diversidade de atrações e hospedagem - contemplados de forma planejada e dinâmica atendendo as necessidades da população para o lazer e oferecendo atrativos turísticos. Os parques urbanos presentes no coração das grandes cidades são de grande importância, por constituírem-se espaços públicos com a presença da natureza; diversidade de práticas de lazer; facilidade de socialização; contemplação/fruição e influenciam na configuração urbana.

Ressalta-se, então, que o "olhar sobre as paisagens urbanas" é diferenciado para cada pessoa, dado que possuem experiências de vida e olhares diversos. A vivência e conhecimento da comunidade com as paisagens de sua cidade, permite a prática do turismo cidadão, que por sua vez, usufruem da diversidade de ambientes que ela proporciona, levando-o a (re)pensar, (re)ver e (re)avaliar as expressões locais (cultura, patrimônio, costumes e arquitetura), ocasionando uma busca por melhor qualidade de vida e preservação da infraestrutura de sua cidade.

Destaca-se ainda, que a cidadania ligada as práticas de lazer e turismo cidadão é uma maneira de repensar comportamentos, atitudes, consumos e etc., praticados nos locais visitados. Com o princípio de respeito mútuo, do visitante em relação à comunidade receptora e vice-versa. 


\section{Referências bibliográficas}

CAMARGO, L.O.L. O que é lazer. São Paulo: Brasiliense, 2003. $2^{\underline{a}}$ reimpr. da 3. ed. de 1992.

CASTROGIOVANNI, A.C. Turismo e ordenação no espaço urbano. In: CASTROGIOVANNI, A.C. (org.). Turismo urbano. 2. ed. (p. 7-9). (p. 23-32). São Paulo: Contexto, 2001a.

CASTROGIOVANNI, A.C. Por que geografia no turismo? Um exemplo de caso: Porto Alegre. In: GASTAL, S. (org.). Turismo 9 propostas para um saber-fazer. $2^{\underline{a}}$ ed. (p. 131-143). Porto Alegre: EDIPUCRS, 2001b. (Coleção Comunicação, 4).

COVRE, M.L.M. O que é cidadania. São Paulo: Brasiliense, 2001.

DIAS, K. Entre visão e invisão: paisagem [por uma experiência da paisagem no cotidiano]. 1 ed. Brasília: Programa de Pós-Graduação em Artes / VIS. Universidade de Brasília - UNB. 2010.

DUMAZEDIER, J. Valores e conteúdos culturais do lazer. São Paulo, SESC, 1980.

DUMAZEDIER, J. Lazer e cultura popular. 3. ed. São Paulo: Perspectiva, 2004. ESTATUTO da cidade. Disponível em:

$<$ https://www.planalto.gov.br/ccivil 03/Leis/LEIS 2001/L10257.htm>. Acesso em: 02 ago. 2011.

FRANCO, M.A.R. Desenho ambiental: uma introdução à arquitetura da paisagem com o paradigma ecológico. São Paulo: Annablume: FAPESP, 1997.

FUSTER, L.F. Teoría y Técnica del Turismo. 4. ed. San Agustín, Madrid. Tomo I. 1974.

GASTAL, S. O produto cidade: caminhos de cultura, caminhos de turismo. In: CASTROGIOVANNI, A.C. (org.). Turismo urbano. 2. ed. (p. 33-42). São Paulo: Contexto, 2001.

GASTAL, S.; MOESCH, M.M. Turismo, políticas públicas e cidadania. São Paulo: Aleph, 2007.

KLIASS, R.G. Parques urbanos de São Paulo e sua evolução na cidade. São Paulo: Pini, 1993.

KRIPPENDORF, J. Sociologia do turismo: para uma nova compreensão do lazer e das viagens. Tradução: Contexto traduções. 3. ed. rev. e ampli. São Paulo: Aleph, 2009.

MARCELLINO, N.C. Estudos do lazer: uma introdução. Campinas, São Paulo: Autores Associados, 1996. (Coleção educação física e esportes).

MARCELLINO, N.C. Lazer e humanização. 7. ed. Campinas: Papirus, 2003. 
MOLINA, S. Fundamentos del nuevo turismo. 3. ed. 2005. Mexico.

RIBEIRO, M. A atratividade dos centros urbanos e o Turismo. In: GASTAL, S. (org.). Turismo 9 propostas para um saber-fazer. $2^{\mathrm{a}}$ ed. (p. 145-150). Porto Alegre: EDIPUCRS, 2001. (Coleção Comunicação, 4).

SENNETT, R. Carne e pedra. Tradução: Marcos Aarão Reis. $2^{\circ}$ ed. Rio de Janeiro: Record, 2001.

SERPA, A. O espaço público na cidade contemporânea. São Paulo: Contexto, 2007.

SILVA, M.G.L. Cidades turísticas: identidades e cenários de lazer. São Paulo: Aleph, 2004. (Série Turismo).

SPIRN, A. W. O jardim de granito: a natureza no desenho da cidade. Tradução: Paulo Mesquita Pellegrino. São Paulo: Edusp, 1995.

\section{Notas:}

A partir de 1740, os grandes centros europeus começaram a cuidar da limpeza urbana, com a consecução de: drenagem de buracos e depressões alagadas; uso de materiais nas calçadas, como placas de granito, que evitassem fissuras para não acumular excrementos humanos e de animais. Em 1750, o povo parisiense foi obrigado a lavar o estrume e o entulho em frente à residência. Houve a recuperação de locais inundados ou obstruídos em 1764. E, em 1780, foi proibido esvaziar os penicos nas ruas (SENNETT, 2001, p. 220).

${ }^{2}$ Bricolage - consertos, reparos, execução de pequenos trabalhos, ligados aos ofícios (DUMAZEDIER, 1980, p. 130).

${ }^{3}$ Semilazer - Parte da ideia de tornar-se outro trabalho exercido no tempo liberado do trabalho profissional, como as atividades ligadas às obrigações familiares. Dumazedier (1980, p. 166) diz que as atividades socioespirituais e sociopolíticas estão inclusas no tempo liberado tanto do trabalho quanto das obrigações familiares.

${ }^{4}$ No que se refere ao interesse turístico pela cultura, Gastal (2001, p. 121) afirma que "a cultura apropriada pelo Turismo é a cultura que gera produtos e manifestações concretas, sejam elas eruditas ou populares". No entanto, "a cultura passará a ser veículo de socialização entre visitantes e visitados, quando ela for um processo vivo de um fazer de uma determinada comunidade" (p. 127). Ainda, a "cultura é um insumo turístico importante, mas é aquela cultura viva, praticada pela comunidade em seu cotidiano" (p. 129).

${ }^{5}$ Termo anulado pelas autoras Gastal e Moesch.

6 "A pólis era composta de homens livres, com participação política contínua numa democracia direta, em que o conjunto de suas vidas em coletividade era debatido em função de direitos e deveres", segundo Covre. (2001, p. 16). 
${ }^{7}$ Os direitos civis são aludidos com os direitos de se dispor do próprio corpo, locomoção, segurança, liberdade de expressão, etc. Os direitos sociais constroem a concepção de cidadania. Concerne ao atendimento das necessidades humanas básicas - salário decente, direito à saúde, à educação, à habitação, dentre outros - repondo a força de trabalho e o sustento do corpo humano. Os direitos políticos referem-se aos dois outros direitos supramencionados, assim os três são dependentes e co-relacionados. Este direito diz respeito à liberdade de expressar à opinião, o pensamento, à ideologia religiosa, à prática política etc. (COVRE, 2001).

Mariana Inocêncio Oliveira Melo: Universidade de Brasília, Brasília, DF, Brasil. Email: mariinocencio@gmail.com

Link para o currículo Lattes: http://lattes.cnpq.br/5281775927412547

Karina e Silva Dias: Universidade de Brasília, Brasília, DF, Brasil.

Email: karinadias.net@gmail.com

Link para o currículo Lattes: http://lattes.cnpq.br/5090396987995001

Data de submissão: 30 de junho de 2012

Data de recebimento de correções: 16 de junho de 2013

Data do aceite: 20 de setembroo de 2013

Avaliado anonimamente 